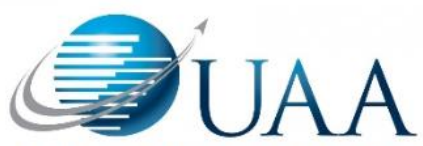

Collegiate Aviation Review

International

UNIVERSITY AVIATION

ASSOCIATION

$12-07-2021$

\title{
Effective Social Media Strategy for Collegiate Aviation Programs
}

Irene Miller

Southern Illinois University

Timm Bliss

Oklahoma State University

As Generation $\mathrm{Z}$ becomes college aged, establishing an effective presence on social media is becoming increasingly important for higher education institutions. Prospective students are using social media to help guide them in their college decisions, which illustrates why it is increasingly important to have an effective social media strategy. The Oklahoma State University School of Educational Foundations, Leadership, and Aviation has gathered important information from social media analytics and industry resources that assists in the development of an effective social media strategy. Other collegiate aviation programs can use this information to develop or refine their existing social media strategies.

Recommended Citation:

Miller, I. \& Bliss, T. (2021). Effective social media strategy for collegiate aviation programs. Collegiate Aviation Review International, 39(2), 258-265. Retrieved from

http://ojs.library.okstate.edu/osu/index.php/CARI/article/view/8394/7688 


\section{Introduction}

It is important for collegiate aviation programs to understand the importance of developing and refining an effective media strategy. An important component of an effective media strategy is the development of the collegiate aviation program's brand image. Every collegiate aviation program has a brand image, so it is important to establish a compelling brand image. What is more, an effective social media strategy will assist collegiate aviation program recruitment, engagement, and promotion of core values. The Oklahoma State University (OSU) School of Educational Foundations, Leadership, and Aviation has shared with the researcher what social media practices have worked well and what practices were ineffective. Also, collegiate aviation programs need to be adaptive as social media platforms continue to evolve in the future.

\section{Why is developing a social media strategy important?}

It is important for collegiate aviation programs to learn about their target audience, Generation $Z$ before they develop a social media strategy. Thirty percent of students reached a university's website through the university's social media platform. Generation Z students are increasingly relying on social media platforms to guide their decisions regarding which university they will attend. They are quick to determine if they are interested in a social media post, so engaging and compelling posts are important. Furthermore, the students do not respond to aggressive marketing and sales tactics (Upton, 2019).

To appeal to the target audience, the social media posts need to be authentic, personalized, user friendly, and well designed. Eighty percent of students indicate "authenticity of content" is an influencing factor on social media platforms (Mendes, n.d.). Posts need to provide information students find useful and interesting. The social media platform needs to be user-friendly because $62 \%$ of students will leave a social media platform if it is not easy to navigate (Rhyneer, 2021). Next, the social media platform needs to be well designed. Eightyseven percent of students indicate an effectively managed social media platform improves their opinion of a university (Rhyneer, 2021).

It is paramount for collegiate aviation programs to understand demographics for Instagram and Facebook to ensure the correct posts are being placed on the appropriate platforms. Thirty percent of internet users have an Instagram account, and $90 \%$ are under 35 years old, and $60 \%$ of Instagram users $\log$ in to their accounts daily (Upton, 2019). Instagram has over 1 billion monthly active users, over 500 million daily Instagram Story users, and a $4.21 \%$ engagement rate (Mendes, n.d.).

Engagement rate is determined by the amount of engagement divided by the number of followers. Engagement is defined as the number of user interactions with content. Instagram's 
engagement rate is much higher than Twitter and Facebook. Conversely, Facebook users are over 35 years old, which is the social media platform used by alumni and parents, and has 2.3 billion monthly active users (Mendes, n.d.).

\section{Determine Your Brand Image}

When developing a brand image, there are several crucial questions that need to be answered. The answers to these questions will provide the collegiate aviation program with the information needed to develop an effective brand image.

$\circ$ What are the program's core values?

$\circ$ Who is the target audience? What content does the target audience want to see?

- What are the program's goals?

- How will the program engage the target audience?

$\circ$ What are the competitors doing?

All collegiate aviation programs have a brand image, so the goal is to develop and refine the brand image to accurately represent the program's mission statement. Videos and photos are very compelling, so Instagram, being an image-heavy platform, is very effective at building a brand image. The brand image conveys the program's mission statement, which should coincide with the university's mission statement. This consistency is needed because many students will link from the university's social media platforms to the program's social media platforms. Furthermore, collegiate aviation programs need to maintain consistency across their social media platforms.

Oklahoma State University's brand image encompasses diversity, family atmosphere, and the Cowboy Code. OSU's aviation program uses social media to celebrate diversity by posting content that celebrates events such as National Hispanic and Pride months. OSU seeks to promote a sense of community amongst their students. They achieve this through announcing social events on social media, such as "Movie Nights" at the Cowboy Hangar. This social involvement amongst students promotes the value of a family atmosphere, as it is important for students to feel as if they are a part of a community. Finally, the Cowboy Code conveys the foundational values that direct OSU's brand image on social media platforms. The posts on social media need to adhere to and promote those values provided in the Cowboy Code.

An effective brand image will establish the program as the "must attend" collegiate aviation program. Remember that brand image is paramount as $58 \%$ of aspiring students use social media platforms to investigate schools they are considering (Sehl, 2020). Of those students that use social media platforms to investigate schools they may attend, $17 \%$ stated the school's social media platform was extremely influential when making their decision of which school to attend, while 61\% stated it was somewhat influential (Sehl, 2020).

\section{Recruitment}

To effectively recruit students for the program, the program must first understand the values of these aspiring students. Aspiring students value:

○ Inclusion 


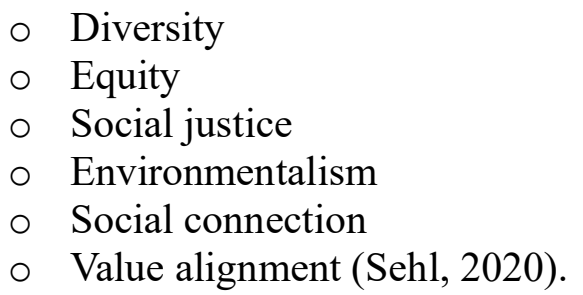

It is important to understand that the presence of inclusionary policies within a collegiate aviation program will promote diversity. Aspiring students need to know the program values differences among people. Furthermore, students want to see the promotion of social connection within the program. They want to feel like they will be part of a community if they attend the program. The values listed above can be promoted on a program's social media platforms. This will enable students to achieve value alignment with the program. It is important for the program to demonstrate that the program's values align with the students' values.

To effectively recruit, it is necessary to feature faculty, alumni, and staff to establish these individuals as leaders in the industry. Feature their industry experience, publications, research, and awards. This will allow the program to convey to students how the program can help them achieve their career goals. In addition to the industry leaders associated with the program, it will be important to highlight internships, pathway programs, and job placement statistics as they will enable students to see tangible evidence of the program's ability to help them achieve their career goals.

Lastly, for the purpose of recruitment, it is essential for students to envision themselves at the university. Feature campus life through virtual tours and photos. For example, you can post appealing photos of the campus on Instagram or a list of the top 10 places to hang out on campus. This will assist the student when answering the question - Can I see myself there?

\section{Promotion of Core Values}

Social media platforms can help collegiate aviation programs promote their core values. First, the program needs to determine its core values. What values does the program stand for? This question needs to be answered first, and the answer will be unique for every program. How will the program promote those core values? It is important for the program's core values to be consistent with those of the university. Also, it is necessary for the program to remain consistent across the social media platforms when promoting core values. Your program can start by promoting the "value of a degree" in aviation. Why should students pursue a degree in aviation? Highlight the positive aspects of pursuing a career in aviation and the opportunities within the industry.

Posts that feature statistics about flight operations, including the number of flight hours safely flown over the past year, convey to users the program values safety. Featuring scholarships for minoritized populations and student organizations for minority students promote diversity and inclusion. This will assist a student when answering the question - Are there others that are like me at the program? Conveying the program's core values allows students to achieve 
value alignment with your program. Students experience value alignment with the program, meaning the students have the same values as the program.

\section{Engagement}

Engagement on social media platforms is important to Generation Z students. These students are looking for more than "likes" on social media posts. They want to see students, faculty, parents, and alumni interacting with each other on social media. This develops a sense of community that students value as they want to feel as if they are part of a community where they will be accepted and flourish. Instagram is very effective at promoting user engagement. There are many methods that can be used to promote engagement; however, there are several that have shown to be very effective such as "takeovers." There are alumni, faculty, and student takeovers that enable a specific individual to take over the program's social media account for the day. For example, an alum can take over the social media account while they are at work and post pictures and videos highlighting their careers. The alum is also available throughout the day to interact with students and faculty and answer questions. Some programs have students who are social media ambassadors who are involved with managing the programs' social media platforms and performing student takeovers. It is imperative that the individuals conducting the social media takeovers are well screened and understand the program's brand image to avoid any problematic posts.

Featured posts are another great way to promote engagement on social media platforms. For instance, engagement amongst alumni can be encouraged through "Throwback Thursday" posts. It is helpful to feature alumni in "where are they now" posts as it gives alumni a chance to reconnect with prior classmates. This also provides confidence in the program from aspiring students as this demonstrates that the program will successfully prepare them for the career they are seeking in the aviation industry.

There are many ways to engage students on social media. Pictures and videos are featuring "Top 10 Lists" of things to do around campus. Another option is to post contests, polls, and games for students. Another option is to encourage students to post about themselves so ask students to post pictures and videos asking students to "check in" and let everyone know where and what they are doing during the summer. Encourage students to use specific hashtags when they post. Finally, engagement can be promoted by simply providing useful information regarding events and important dates. Students respond favorably to information they find useful, such as scholarship and internship deadlines. Also, student organizations can post information about social events and ask students to use a poll to indicate if they plan on attending.

\section{What Works}

There are a few things collegiate aviation programs can do to assist with developing a successful social media strategy.

○ The use of a content calendar is recommended for several reasons. A content calendar assists with focusing on the overall strategy rather than daily posts. However, it is important to remain flexible and make unscheduled posts when needed. The calendar 
will also help keep track of important dates, deadlines, and holidays. More importantly, scheduled posts will help the program avoid posts that may be problematic.

- The development of Key Performance Indicators linked to analytics will help the program set goals and evaluate the efficacy of the social media strategy.

- A "trial and error approach" is needed to determine what works for the program's social media platforms.

- The use of hashtags works well at promoting content. You should create some of your own hashtags and use 3-5 hashtags for each post. Hashtags identify who you are and should correspond with your brand.

It is important to remember that engagement is a key component of a successful social media strategy. The following types of posts are effective at creating engagement:

- New and interesting pictures

- Compelling videos

- Student achievement

○ Opportunities for students

\section{What Works - Instagram}

- On Instagram, the target audience is junior high students through mid/late 20s, so posts on Instagram need to target students and younger alumni from the program. It is imperative the content posted appeals to this demographic, as they are the target audience (Upton, 2019).

- Interactive posts are popular on Instagram if they are simple. Interactive posts that require multiple steps are typically not well received.

- An Instagram story is a great way to convey information quickly to students.

\section{What Does Not Work?}

- Any post that is placed on a platform with the incorrect target audience. For example, if a post's target audience is students, the post should not be placed on Facebook because the students are not on Facebook.

- A "cookie-cutter approach" is not effective because each program is unique. What works for one collegiate aviation program may not necessarily work for another.

- Be certain to research hashtags before using them.

\section{What is Next?}

You may want to consider using these social media platforms in the future, as these social media platforms are becoming increasingly popular with junior high through college students.

○ TikTok

- Snapchat

○ Instagram Reels

Social media will continue to evolve over time, requiring the adjustment of the program's social media strategy. Social media platforms will continue to become an increasingly important 
tool for collegiate aviation programs to communicate, recruit, engage, and convey core values. Social media can provide many positive results for collegiate aviation programs but can become a liability if not managed properly. It is advised to answer the following questions before posting on social media.

$\circ$ Who is the target audience?

- Is the program posting on the correct social media platform to reach the target audience?

○ Does this post convey our core values?

- How will the target audience receive this post? 


\section{References}

Mendes, M. (n.d.). Why social media data collection is essential for marketing. Pixlee. Retrieved from: https://www.pixlee.com/blog/why-social-media-data-collectionis-essential-for-marketing/

Rhyneer, M. (2021, June 1). How to effectively reach Gen $\mathrm{Z}$ in 2021. EAB. Retrieved from: https://eab.com/insights/blogs/enrollment/effectively-reach-gen-z/

Sehl, K. (2020, August 19). Social media in higher education: 8 essential tips. Hootsuite. Retrieved from: https://blog.hootsuite.com/social-media-in-higher-education/

Upton, E. (2019, May 27). Gen Z wants an authentic experience. Use these Snapchat and Instagram features to deliver it. $E A B$. Retrieved from: https://eab.com/insights/blogs/enrollment/gen-z-wants-an-authentic-experience-usethese-snapchat-and-instagram-features-to-deliver-it/ 